\title{
Gaps in the coverage of vitamin $\mathrm{K}_{1}$ prophylaxis among newborns in India: insights from secondary analysis of data from the Health Management Information System
}

\author{
Kaustubh Bora* \\ Haematology Division, ICMR - Regional Medical Research Centre, North East Region, Dibrugarh 786010, Assam \\ (Department of Health Research, Ministry of Health \& Family Welfare, Government of India)
}

Submitted 24 February 2021: Final revision received 30 July 2021: Accepted 23 August 2021: First published online 25 August 2021

\begin{abstract}
Objective: Despite operational guidelines, anecdotal evidence suggests that newborn vitamin $\mathrm{K}_{1}$ prophylaxis is not practiced routinely in India. This study determined the coverage of vitamin $\mathrm{K}_{1}$ prophylaxis among newborns in the country. Design: Nationwide cross-sectional data on live births and newborns receiving vitamin $\mathrm{K}_{1}$ during the 2019-2020 reporting period were abstracted from the Health Management Information System (HMIS). The coverage estimates of newborn vitamin $\mathrm{K}_{1}$ prophylaxis were derived nationally and also for individual states and union territories (UT). Additionally, coverage heterogeneities were investigated using classifiers, viz. geography, socio-demographic index (SDI), special developmental categories and institutional birth rate (IBR).

Setting: India.

Participants: 20208804 newborns documented with HMIS.

Results: Vitamin $\mathrm{K}_{1}$ was administered to overall $62.36 \%$ newborns (95\% CI: 62.34 to $62.38 \%)$. The Central zone (49.0\%), low SDI states (54.39\%), Empowered Action Group states (53.32\%) and states with low IBR (44.69\%) had the lowest coverage amongst their respective groupings. Across the individual states and UT, the coverage ranged widely from $22 \cdot 18 \%$ (in Tripura) to $99 \cdot 38 \%$ (in Puducherry), exhibiting considerable variability (coefficient of variation: $33.74 \%$ ) and inequality (Gini coefficient: 0.17). While the coverage in eight states/UT (i.e. Arunachal Pradesh, Manipur, Nagaland, Tripura, Uttar Pradesh, Uttarakhand, Telangana and Andaman \& Nicobar Islands) was below $50 \%$; only five states/UT (i.e. Chandigarh, Gujarat, Goa, Puducherry and Tamil Nadu) achieved above $90 \%$ coverage.

Conclusion: Vitamin $\mathrm{K}_{1}$ prophylaxis was not practiced in more than one-third newborns in India. It calls for identifying the barriers, addressing the gaps and implementing newborn vitamin $\mathrm{K}_{1}$ prophylaxis more effectively throughout the country.
\end{abstract}

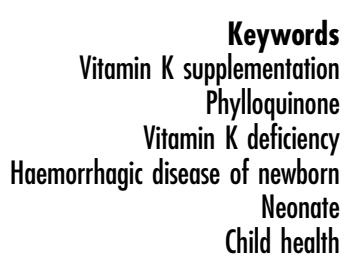

Vitamin K refers to fat-soluble vitamins with a 2-methyl-1,4naphthoquinone nucleus, which includes the natural vitamers phylloquinone (vitamin $\mathrm{K}_{1}$ ) and menaquinone (vitamin $\mathrm{K}_{2}$ ) and the synthetic product menadione (vitamin $\mathrm{K}_{3}$ ). Vitamin $\mathrm{K}$ is an essential cofactor for the synthesis of functionally active liver-derived coagulation factors (II, VII, IX and $\mathrm{X}$ ) in the body ${ }^{(1,2)}$. Thus, inadequate vitamin $\mathrm{K}$ may lead to vitamin $\mathrm{K}$ deficiency bleeding (VKDB) - a clinical entity characterised by haemorrhagic tendency ${ }^{(1-3)}$.

Though known for about a century, VKDB is still encountered globally ${ }^{(3-9)}$. The risk of VKDB is particularly high during early infancy ${ }^{(3,4)}$. The onset may be 'early' (within first $24 \mathrm{~h}$ of birth), 'classical' (between 1 and $7 \mathrm{~d}$ of birth) or 'late' (between 2 and 12 weeks of life usually, but may manifest upto 6 months $)^{(2-4)}$. The incidence is higher in low- and middle-income countries, especially for late-onset $\mathrm{VKDB}^{(3,4,10)}$. The bleeding manifestations of VKDB are not always severe, but often produce complications (viz., intracranial haemorrhage, gastrointestinal haemorrhage, etc.) causing significant morbidity or even death $^{(2-4,6)}$. Thus, adequate vitamin $\mathrm{K}$ supplementation in newborns is vital. Towards that end, the WHO advocates intramuscular administration of vitamin $\mathrm{K}_{1}$ prophylactically to newborn babies soon after birth to prevent $\mathrm{VKDB}^{(11)}$. 
India is home to nearly one-fifths of the babies born in the world ${ }^{(12)}$. Despite improvements in child health over the past decades ${ }^{(13,14)}$, the implementation of newborn vitamin $\mathrm{K}$ prophylaxis in India has been slow ${ }^{(15)}$, with anecdotal evidence indicating that it is still not practiced routinely ${ }^{(16)}$. Reliable estimates are unavailable, but VKDB appears to be quite prevalent in the country ${ }^{(8,15,16)}$. In 2014, operational guidelines for prophylactic vitamin $\mathrm{K}$ supplementation in newborns were issued in India under a policy decision to prevent VKDB. As per these guidelines, a prophylactic birth dose of vitamin $\mathrm{K}_{1}$ ( $1 \mathrm{mg}$ to neonates weighing $\geq 1000 \mathrm{~g}$ and $0.5 \mathrm{mg}$ to neonates weighing $<1000 \mathrm{~g}$ ) was recommended intramuscularly for all newborns (not later than $24 \mathrm{~h}$ of delivery) ${ }^{(17)}$. Providing vitamin $\mathrm{K}_{1}$ to neonates is also in alignment with Facility Based Integrated Management of Neonatal and Childhood Diseases (F-IMNCI) guidelines ${ }^{(18)}$, and a component of the intervention package for immediate newborn care recommended under the India Newborn Action Plan ${ }^{(19)}$. To inform these endeavours, this study was undertaken with the objective of determining the coverage of newborn vitamin $K_{1}$ prophylaxis in India. Additionally, the variations in coverage across the country were explored.

\section{Methods}

\section{Data sources and retrieval}

The study used nationwide cross-sectional data from the Health Management Information System (HMIS). The HMIS is an initiative under the National Health Mission with technical assistance from the National Health Systems Resource Centre. It serves as a dedicated single-window web-based platform for gathering and monitoring India's public health information ${ }^{(20,21)}$. The HMIS network mandates regular reporting of health-related information (in the form of count data) under specific headings (called 'data elements') from health facilities spread across the country, using standardised and uniform data reporting forms ${ }^{(20)}$. The data elements pertain to a wide range of health-related events (e.g. infant deaths, complicated pregnancies, pregnant women with severe anaemia, institutional deliveries, etc.) and health services (e.g. Hb tests conducted, pregnant women receiving calcium supplements, vasectomies performed, condoms distributed, immunisation sessions held, etc. $)^{(20,21)}$. This facility-level information is aggregated in a stepwise manner (i.e. successively at the block, district and state levels) for final compilation at the national level. Accordingly, all public health facilities (including subcenters, primary health centers and community health centers) are required to report their data regularly on a monthly basis (before the 5 th of the following month) for compilation at the block level (Block Monthly Consolidated Report) and onward transmission to the District Programme Management Unit. The districtlevel public health facilities (viz., district hospitals, civil hospitals) report their monthly data directly to the district headquarters (District Programme Management Unit). The District Programme Management Unit aggregates this data along with all block-level monthly data from the district to generate the District Monthly Consolidated Report. This district report is submitted to the state headquarters, which then consolidate such reports from all the districts in the state to prepare the State Aggregated Report. Finally, all the state-level reports are consolidated to prepare the national report. The reporting and aggregation of data in HMIS are computerised. The HMIS also allows reporting of data from private health facilities, which may report either at the block level or directly at the district level ${ }^{(20)}$

The HMIS data for a particular financial year (i.e. AprilMarch) is made available in the public domain (https:// hmis.nhp.gov.in/\#!/). In this study, relevant data elements (described below) pertaining to the thirty-six administrative units of India (twenty-nine states and seven union territories (UT)) were abstracted from the HMIS for the 2019-2020 reporting period (i.e. April 2019-March 2020). Since the HMIS collects and compiles deidentified data from health facilities in India and hosts it in the public domain, therefore ethical approval and informed consent were not required.

\section{Definitions and data elements}

Coverage of vitamin $\mathrm{K}_{1}$ prophylaxis in newborns was defined as the percentage of newborn children who were administered the birth dose of vitamin $\mathrm{K}_{1}$. It was determined using the data element "Child immunisation Vitamin K1 (Birth Dose)' as numerator and the sum of the data elements 'Live Birth - Male' and 'Live Birth Female' as denominator (see online Supplemental Table 1).

The National Immunization Schedule under the Universal Immunization Programme in India recommends all newborn babies to be protected with the birth doses (also known as zero doses) of hepatitis B vaccine (HBV) and oral polio vaccine $(\mathrm{OPV})^{(22,23)}$. Similar to vitamin $\mathrm{K}_{1}$ prophylaxis, the HBV birth dose is injected intramuscularly soon after delivery (and not later than $24 \mathrm{~h}$ ). Due to the common schedule and route, vitamin $\mathrm{K}_{1}$ and HBV are administered to a newborn child at the anterolateral aspect of separate thighs ${ }^{(17,23)}$. The birth dose of OPV is provided orally as early as possible after birth (and within the first 15 $\mathrm{d}$ of life). While OPV was introduced into India's routine immunisation since the 1980s, the inclusion of HBV and vitamin $\mathrm{K}_{1}$ prophylaxis into India's routine newborn care services is relatively recent (since 2007 and 2014, respectively). Considering the operational similarities and dissimilarities, the coverage of vitamin $\mathrm{K}_{1}$ prophylaxis in newborns was compared and contrasted with that of $\mathrm{HBV}$ and OPV immunisation in newborns. As shown in Supplemental Table 1, the data elements "Child immunisation - OPV O (Birth Dose)' and 'Child immunisation - Hepatitis-BO 
(Birth Dose)' were used to assess the coverage of OPV and HBV birth doses, respectively.

Institutional birth rates (IBR), i.e. percentage of births occurring in health facilities, were determined from the number of births in health facilities (available from the data element 'Number of Institutional Deliveries conducted Including C-Sections') and the total number of births (given by sum of three data elements: 'Live Birth - Male', 'Live Birth - Female' and 'Still Birth') (see online Supplemental Table 1).

\section{Data quality and validation}

The HMIS has provisions for addressing data entry mistakes and systemic errors. These include quality-check mechanisms and guidelines, viz., black/zero examination, duplication checks, usage of consistent terminologies, standardised and uniform formats for reporting data, detection of outliers, visual checks, validation checks, etc. In addition, there are mechanisms in the HMIS to monitor the completeness and timeliness of the reported data (e.g. data status reports, data-filled summary reports, etc.) ${ }^{(21)}$. The current study further interrogated the abstracted data using the following data validation rules: (a) number of newborns receiving vitamin $\mathrm{K}_{1}$ birth dose cannot exceed total live births; (b) number of newborns receiving OPV birth dose cannot exceed total live births; (c) number of newborns receiving HBV birth dose cannot exceed total live births and (d) number of institutional deliveries (including caesarean sections) cannot exceed total births (i.e. sum of live births and stillbirths). In five states/UT, at least one of these rules was violated, viz: (i) Goa (in one district); (ii) Gujarat (in twenty-six districts); (iii) Dadra \& Nagar Haveli (in entirety); (iv) Daman \& Diu (in one district) and (v) Lakshadweep (in entirety) (see online Supplemental Table 2). Data from these particular units (for both numerator and denominator) were deemed unsuitable and excluded from the study.

\section{Subgroups}

India is a vast and populous country with marked diversity in health and healthcare challenges ${ }^{(24,25)}$. Therefore, vitamin $K_{1}$ coverage in this study was probed by various subnational groupings. The states/UT were classified for subgroup analysis into six geographical regions or zones (i.e. Eastern, Western, Northeastern, Central, Northern and Southern zones) as specified under States Reorganization Act 1956 and North Eastern Council Act 1971 (see online Supplemental Table 2).

The states/UT were also categorised by their socio-demographic index into three subgroups: low-, middle- and high-socio-demographic index (see online Supplemental Table 2). The socio-demographic index is a collective measure of developmental status that incorporates lag-distributed per capita income, total fertility rate in people $<25$ years age and mean education of people aged $\geq 15$ years $\operatorname{age}^{(24,25)}$.

Moreover, three 'special developmental categories' recognised by the government (viz., Empowered Action Group states, the Northeast (NE) states and the 'Other' states) were considered for subgroup analysis (see online Supplemental Table 2). In terms of development, the Empowered Action Group states (eight densely populated and poor-performing states with high disease burden) and the NE states (eight remote and hilly states in the northeastern corner of India, having substantial tribal population, limited industrialisation and poor health infrastructure) usually lag behind the 'Other' states (i.e. the remaining states and UT, other than the Empowered Action Group and NE states) ${ }^{(24,26,27)}$. The special developmental schemes in India are often directed at the Empowered Action Group and NE states ${ }^{(24,27)}$.

Lastly, depending upon the IBR values (overall: 93.9\%; range: 59.1-99.4\%; median: 96.5\%), the states/UT were stratified into three groups by tertiles, viz., T1 or low IBR (<93.8\%); T2 or medium IBR (93.8 to $97.8 \%$ ) and T3 or high IBR (> 97.8\%) (see online Supplemental Table 2).

\section{Statistical analysis}

The coverage (\%) of vitamin $\mathrm{K}_{1}$ prophylaxis at birth among newborns was determined nationally (overall India) and subnationally (for the individual states/UT). The corresponding $95 \%$ confidence interval (CI) was calculated by Wilson score method. As described above, the coverage of HBV and OPV birth prophylaxes were also estimated for comparisons with vitamin $\mathrm{K}_{1}$ prophylaxis. The variations in the coverage of vitamin $\mathrm{K}_{1}, \mathrm{HBV}$ and OPV among the states/UT were analysed with the help of coefficient of variation (CV) and Gini coefficient (GC). The CV (ratio of $\mathrm{SD}$ to mean, in percentage) indicated variability in coverage, with a higher $\mathrm{CV} \%$ value denoting greater variability. Alternatively, the GC value reflected inequality in coverage ${ }^{(28-30)}$. Lorenz curves depicting inequalities in vitamin $\mathrm{K}_{1}$, HBV and OPV birth prophylaxis coverage were constructed for calculating the respective GC values (corresponds to twice the area between the Lorenz curve and the equality diagonal i.e. line of perfect equality). Farther the Lorenz curve is from the diagonal, greater the GC and greater the degree of inequality.

Variations in the coverage of vitamin $\mathrm{K}_{1}$ prophylaxis were also assessed across subgroups. The 'between subgroup' coverage variations under a grouping were quantified using coverage differences and coverage ratios, with the highest performing subgroup (in that grouping) serving as the reference. The accompanying 95\% CI estimates were derived by Taylor series expansion variance approximation method. On the other hand, the coverage variations 'within a subgroup' were captured using CV \% and GC, computed from the coverage rates in the states/UT belonging to that particular subgroup. Data were analysed with 
the help of Microsoft Excel (Microsoft Office Professional Plus 2019, Microsoft Corp.) and OpenEpi v3.0.1 (http:// www. OpenEpi.com) programs.

\section{Results}

A total of 20208804 live births documented with HMIS during the 2019-2020 reporting period were considered, out of which vitamin $\mathrm{K}_{1}$ prophylaxis was administered to 12601641 newborns (62.36\%; (95\% CI 62.34, 62.38)) (Table 1). The coverage ranged from $22 \cdot 18 \%$ (in Tripura) to $99.38 \%$ (in Puducherry) among the different states and UT (Fig. 1). Eight states/UT-Arunachal Pradesh, Manipur, Nagaland, Tripura, Uttar Pradesh, Uttarakhand, Telangana and Andaman \& Nicobar Islands-had coverage below $50 \%$. Of these, three states/UT (Tripura, Nagaland and Andaman \& Nicobar Islands) had coverage below $25 \%$. Only a handful of states/UT (viz. Chandigarh, Gujarat, Goa, Puducherry and Tamil Nadu) achieved coverage values above $90 \%$. Coverage of newborn vitamin $\mathrm{K}_{1}$ prophylaxis differed by various subgroups (Table 1). A greater proportion of newborns received vitamin $\mathrm{K}_{1}$ in the Southern zone (76.66\%), high-socio-demographic index states (75.08\%), 'Other' states (74.03\%) and states/UT with high IBR (79.12\%) than the other subgroup(s) in their respective groupings.

Notably, during the same reporting period, the coverage of the birth doses of OPV (86.70\%; (95\% CI 86.68, 86.71)) and $\mathrm{HBV}(71.41 \%$; (95 \% CI 71.39, 71.43)) were superior to that of vitamin $\mathrm{K}_{1}$ (Table 2 ). Out of the three, vitamin $\mathrm{K}_{1}$ also displayed greater variations in coverage-in terms of both CV $(33.74 \%)$ and GC $(0 \cdot 17)$. Coverage inequality was the highest for vitamin $\mathrm{K}_{1}$, as seen from the Lorenz curves (Fig. 2). The superior coverage rates of OPV and HBV birth doses (as compared to vitamin $\mathrm{K}_{1}$ prophylaxis) were noticed in most states/UT of the country (see online Supplemental Table 3). However, in some states/UT (viz., Assam, Chandigarh, Goa, Gujarat, Himachal Pradesh, Jharkhand, Maharashtra, Meghalaya, Mizoram, Odisha), the coverage of vitamin $\mathrm{K}_{1}$ prophylaxis was better than that of HBV and/or OPV. In Tamil Nadu and Puducherry, the coverage rates for the three prophylaxes were fairly comparable.

Grouping-wise comparisons revealed varying levels of 'between subgroup' and 'within subgroup' heterogeneities in vitamin $\mathrm{K}_{1}$ coverage (Table 3 ). The maximum 'between subgroup' differences were noticed across the IBR-based subgroups, wherein vitamin $\mathrm{K}_{1}$ was administered in the states/UT with low IBR to $34.43 \%$ fewer newborns and 0.56 times less frequently than in the states/UT with high IBR (reference category). The states/UT with low IBR also had the highest 'within subgroup' co-efficient of variation (CV: $40.73 \%$ ), whereas the states in the Central zone exhibited the greatest coverage inequalities (GC: 0·18).

\section{Discussion}

Considerable gaps and inequalities were observed in the coverage of vitamin $\mathrm{K}_{1}$ prophylaxis among newborns in India. Overall, less than two-third newborns in the country received vitamin $K_{1}$ during the $2019-2020$ period. The study findings have important policy implications. First, the fact that more than one-third babies were left out of

Table 1 Coverage of vitamin $\mathrm{K}_{1}$ prophylaxis in newborns across India, overall and by subgroups, 2019-2020

\begin{tabular}{|c|c|c|c|c|}
\hline Grouping/subgroups & $\begin{array}{l}\text { Newborns receiving vitamin } \mathrm{K}_{1} \\
\text { prophylaxis at birth, } n\end{array}$ & Total livebirths, $n$ & $\begin{array}{l}\text { Coverage of newborn } \\
\text { vitamin } \mathrm{K}_{1} \text { prophylaxis, } \%\end{array}$ & $95 \% \mathrm{Cl}$ \\
\hline National (overall) & 12601641 & 20208804 & $62 \cdot 36$ & $62 \cdot 34,62 \cdot 38$ \\
\hline \multicolumn{5}{|l|}{ Zonal grouping } \\
\hline Eastern & 3052448 & 4734374 & 64.47 & $64.43,64.52$ \\
\hline Western & 1417008 & 1952538 & $72 \cdot 57$ & $72 \cdot 51,72 \cdot 64$ \\
\hline Central & 2992120 & 6106366 & $49 \cdot 0$ & $48.96,49.04$ \\
\hline Northeastern & 537575 & 850062 & $63 \cdot 24$ & $63.14,63.34$ \\
\hline Northern & 1748882 & 2842922 & 61.52 & $61.46,61.57$ \\
\hline Southern & 2853608 & 3722542 & $76 \cdot 66$ & $76 \cdot 61,76 \cdot 70$ \\
\hline \multicolumn{5}{|l|}{ SDI-based grouping } \\
\hline Low SDI & 6197960 & 11396012 & $54 \cdot 39$ & $54.36,54.42$ \\
\hline Middle SDI & 3219734 & 4572226 & $70 \cdot 42$ & $70.38,70.46$ \\
\hline High SDI & 3183947 & 4240566 & 75.08 & $75.04,75.12$ \\
\hline \multicolumn{5}{|l|}{ Developmental grouping } \\
\hline EAG states & 5837356 & 10947515 & $53 \cdot 32$ & $53 \cdot 29,53 \cdot 35$ \\
\hline NE states & 537575 & 850062 & $63 \cdot 24$ & $63.14,63.34$ \\
\hline 'Other' states & 6226710 & 8411227 & 74.03 & $74.0,74.06$ \\
\hline \multicolumn{5}{|c|}{ IBR-based grouping (tertile-based) } \\
\hline Low: T1 $(<93.8 \%)$ & 3248430 & 7269366 & 44.69 & $44.65,44.72$ \\
\hline Medium: T2 (93.8 to $97.8 \%)$ & 4351258 & 6617538 & $65 \cdot 75$ & $65.72,65.79$ \\
\hline High: T3 ( $\geq 97.9 \%)$ & 5001953 & 6321900 & $79 \cdot 12$ & $79.09,79.15$ \\
\hline
\end{tabular}

$\mathrm{Cl}$, confidence interval; EAG, empowered action group; IBR, institutional birth rate; NE states, northeast states; SDI, socio-demographic index. 
Percentage of newborn children receiving Vitamin $\mathrm{K}_{1}$ prophylaxis at birth in India during 2019-20

$75 \cdot 1-100 \%$

$50 \cdot 1-75.0 \%$

$25 \cdot 1-50 \cdot 0 \%$

$0-25.0 \%$
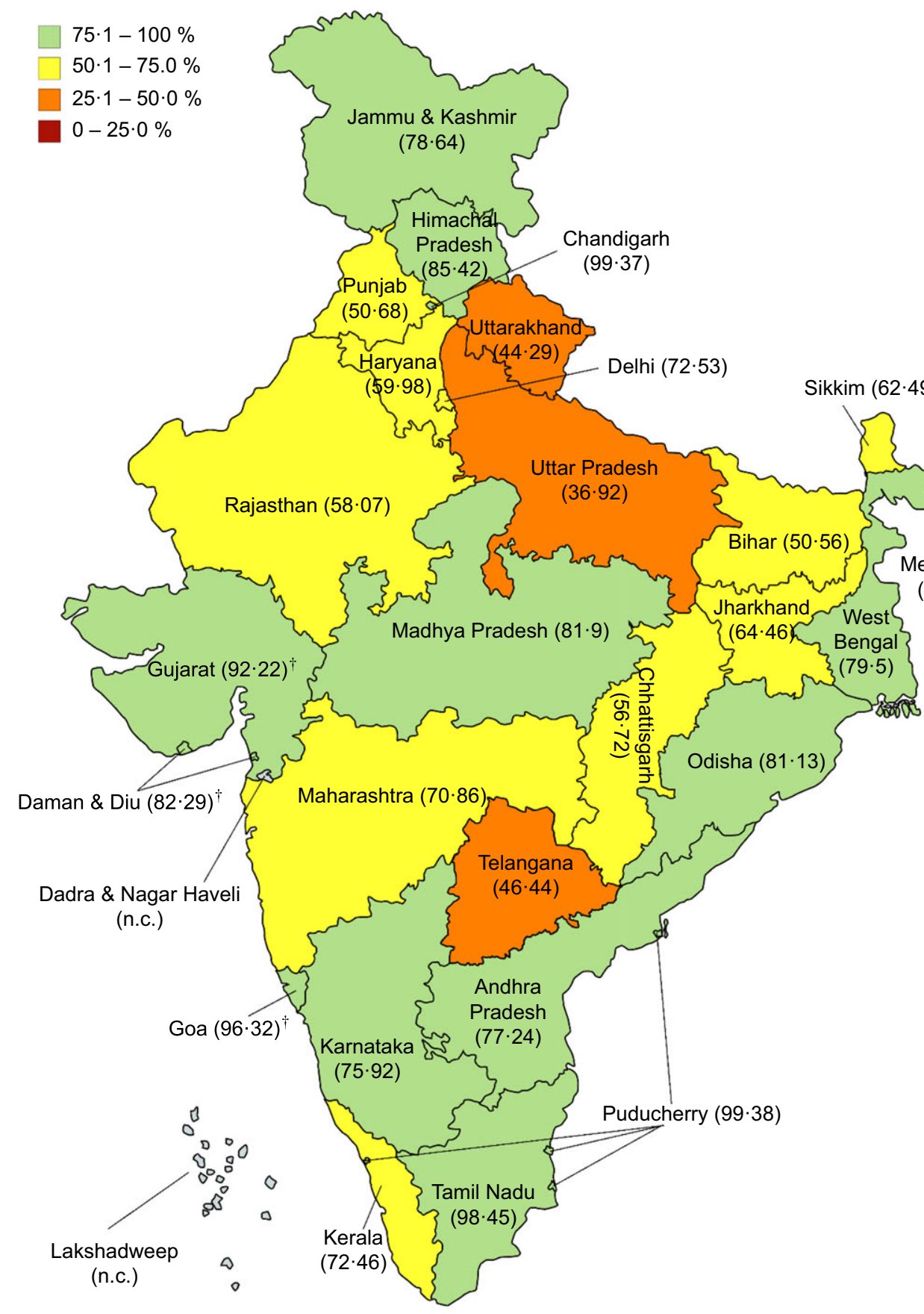

Andaman \& Nicobar Islands

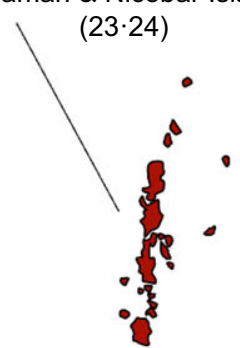

Fig. 1 (colour online) Coverage of vitamin $\mathrm{K}_{1}$ prophylaxis in newborn children at birth in the states and union territories of India, 20192020. ( ${ }^{\dagger}$ Coverage in Gujarat, Goa and Daman \& Diu were estimated in selected districts (details in methodology). Estimates for Dadra \& Nagar Haveli and Lakshadweep were not calculated (n.c.). The state of Jammu \& Kashmir was bifurcated in August 2019 into two union territories, namely 'Jammu \& Kashmir' and 'Ladakh'. The estimates reported against Jammu \& Kashmir in the map are for both the union territories combined)

vitamin $\mathrm{K}_{1}$ prophylaxis despite operational guidelines for universal coverage underscores the need for more effective implementation. Second, the reported differences and inequalities in vitamin $\mathrm{K}_{1}$ prophylaxis would guide regular monitoring and targeted allocation of resources in a needbased manner for redressing the unmet coverage gaps in various parts of the country. Third, given that a considerable proportion of newborns were not covered by vitamin $\mathrm{K}_{1}$ prophylaxis, it is likely that India has a sizeable burden of VKDB. As reliable estimates of VKDB-related burden are currently unavailable, systematic investigations should be initiated. Elsewhere in the world, VKDB surveillance 
Table 2 Coverage of the birth doses of vitamin $\mathrm{K}_{1}$, hepatitis B vaccine (HBV) and oral polio vaccine (OPV) among newborns in India, 20192020

\begin{tabular}{lcccc}
\hline & & & & \multicolumn{2}{c}{$\begin{array}{c}\text { Coverage variations } \\
\text { across the states \& UT } \\
\text { of India }\end{array}$} \\
\cline { 2 - 5 } Prophylaxis & $\begin{array}{c}\text { Newborns receiving } \\
\text { the birth dose, } n\end{array}$ & Coverage, $\%$ & $95 \%$ Cl & CV \% \\
\hline Vitamin $K_{1}$ & 12601641 & 62.36 & $62.34,62 \cdot 38$ & 33.74 \\
HBV & 14431305 & 71.41 & $71.39,71.43$ & 16.69 \\
OPV & 17520812 & 86.70 & $86.68,86.71$ & 12.03 \\
\hline
\end{tabular}

$\mathrm{Cl}$, confidence interval; $\mathrm{CV}$, coefficient of variation; GC, Gini coefficient; HBV, hepatitis B vaccine; OPV, oral polio vaccine; UT, union territory.

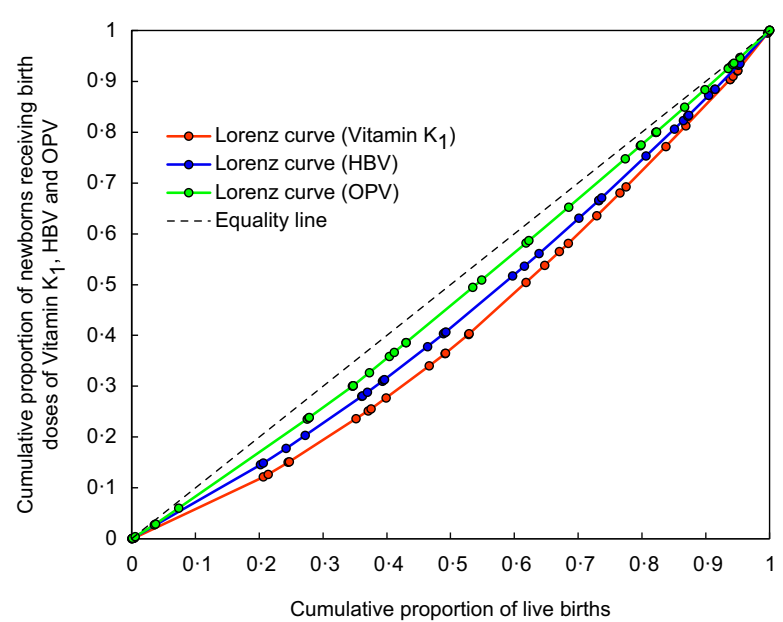

Fig. 2 (colour online) Lorenz curves representing the inequalities in the coverage of vitamin $\mathrm{K}_{1}$, hepatitis $\mathrm{B}$ vaccine (HBV) and oral polio vaccine (OPV) at birth across India

programmes have helped in determining the VKDB-related burden and bolstering the VKDB prevention efforts ${ }^{(4,9,31-33)}$. The feasibility, applicability and benefits of establishing such programmes in the Indian context should be explored.

Although newborn vitamin $\mathrm{K}_{1}$ prophylaxis is regarded as a safe, reliable and cost-effective intervention against VKDB in many countries including $\operatorname{India}^{(2-4,10,11,17,34,35)}$, the challenges to implement it continue to exist ${ }^{(36)}$. Reports from developed countries have increasingly documented instances of parents refusing vitamin $\mathrm{K}_{1}$ prophylaxis in their newborn children ${ }^{(7,9,33,37-39)}$. The common reasons include cultural and religious beliefs (e.g. clotting ability in newborns normalise by 8th d of life), poor awareness about VKDB and its prevention, apprehensions about harm to the baby (e.g. injury, pain, entry of germs, etc.), misinformation (e.g. vitamin $\mathrm{K}_{1}$ predisposes to cancer, etc.) and parental preference for 'alternative' and 'natural' lifestyle ${ }^{(33,36-39)}$. While these are globally relevant issues, a recent online survey brought to light some unique challenges that can hamper vitamin $\mathrm{K}_{1}$ prophylaxis in lowand middle-income countries, viz., high rates of home deliveries, perception among health workers that neonatal vitamin $\mathrm{K}$ prophylaxis is not a priority and supply chain shortcomings $^{(40)}$.

The sizeable proportion of home deliveries in some states of India is indeed an important hindrance to achieving universal newborn vitamin $\mathrm{K}_{1}$ prophylaxis because it precludes the opportunity of contact with skilled manpower (viz., medical officer, staff nurse, auxiliary nurse midwife) for injecting vitamin $\mathrm{K}_{1}$, which is otherwise feasible during institutional deliveries. The differential coverage patterns that emerged across the IBR-based tertiles in this study substantiated that challenge. Geographical location, socioeconomic development and demographic variables were other important factors that affected the coverage. Training of community health workers to administer vitamin $\mathrm{K}_{1}$ injection at home may be a practicable solution to improve compliance ${ }^{(41)}$, at least in areas with high rates of non-institutional deliveries.

The more extensive and less variable coverage of OPV and HBV birth prophylaxes in contrast to vitamin $\mathrm{K}_{1}$ (during the same reporting period) suggests the presence of additional barriers to the successful implementation of the latter. It is true that OPV is relatively easier to administer (skilled manpower not required since the route is oral) and offers a greater window period (upto $15 \mathrm{~d}$ post-delivery). It is also likely that the greater awareness about OPV and HBV (due to regular immunisation drives and awareness campaigns against vaccine preventable diseases) had contributed to their enhanced coverage. However, there are some operational advantages in favour of vitamin $\mathrm{K}_{1}$ prophylaxis, as well. For instance, the stability of vitamin $\mathrm{K}_{1}$ at room temperature obviates the requirement of additional logistics/expenditure for storage and renders it suitable for routine practice even in resource-limited settings ${ }^{(17)}$, unlike $\mathrm{HBV}$ and $\mathrm{OPV}$ that have stringent temperature requirements (stored at +2 to $+8^{\circ} \mathrm{C}$ in ice-lined refrigerators) for maintaining cold chain ${ }^{(23)}$. Moreover, the recommended vitamin $\mathrm{K}_{1}$ preparations are available as small dose vials (either $1 \mathrm{mg} / 1 \mathrm{ml}$ or $1 \mathrm{mg} / 0.5 \mathrm{ml}$ ) ${ }^{(17)}$ that facilitate single-usage and minimal wastage. On the contrary, OPV and $\mathrm{HBV}$ are available as multi-dose vials owing to which health workers may be reluctant to open a new vial for concerns of vaccine wastage (in spite of an 'open vial policy'), more so when the number of deliveries in the health facility 
Table 3 Variations in the coverage of newborn vitamin $\mathrm{K}_{1}$ prophylaxis across India by subgroups, 2019-2020

\begin{tabular}{|c|c|c|c|c|c|c|c|}
\hline \multirow[b]{3}{*}{ Grouping/subgroups } & \multirow{3}{*}{$\begin{array}{c}\text { Newborn vitamin } \mathrm{K}_{1} \text { prophylaxis } \\
\text { coverage, \% }\end{array}$} & \multicolumn{6}{|c|}{ Variations in the coverage of newborn vitamin $\mathrm{K}_{1}$ prophylaxis } \\
\hline & & \multicolumn{4}{|c|}{ Between subgroups } & \multicolumn{2}{|c|}{$\begin{array}{l}\text { Within } \\
\text { subgroup }\end{array}$} \\
\hline & & CD \% & $95 \% \mathrm{Cl}$ & CR & $95 \% \mathrm{Cl}$ & CV \% & $\mathrm{GC}$ \\
\hline India (overall) & $62 \cdot 36$ & - & & - & & - & - \\
\hline \multicolumn{8}{|l|}{ Zonal grouping } \\
\hline Eastern & 64.47 & $-12 \cdot 18$ & $-12 \cdot 24,-12 \cdot 12$ & 0.84 & $0.84,0.84$ & $20 \cdot 82$ & 0.11 \\
\hline Western & $72 \cdot 57$ & -4.09 & $-4 \cdot 16,-4 \cdot 01$ & 0.94 & $0.94,0.95$ & $13 \cdot 29$ & 0.02 \\
\hline Central & $49 \cdot 0$ & $-27 \cdot 66$ & $-27 \cdot 72,-27 \cdot 60$ & 0.64 & $0.63,0.64$ & 35.89 & 0.18 \\
\hline Northeastern & 63.24 & -13.42 & $-13 \cdot 53,-13 \cdot 31$ & 0.83 & $0.83,0.83$ & $40 \cdot 65$ & $0 \cdot 10$ \\
\hline Northern & 61.52 & $-15 \cdot 14$ & $-15 \cdot 21,-15.07$ & 0.80 & $0.80,0.81$ & $23 \cdot 80$ & 0.07 \\
\hline Southern & $76 \cdot 66$ & reference & & reference & & $38 \cdot 89$ & 0.12 \\
\hline \multicolumn{8}{|l|}{ SDI-based grouping } \\
\hline Low SDI & 54.39 & $-20 \cdot 70$ & $-20 \cdot 75,-20 \cdot 65$ & 0.72 & $0.72,0.73$ & 24.52 & 0.17 \\
\hline Middle SDI & $70 \cdot 42$ & -4.66 & $-4 \cdot 72,-4 \cdot 61$ & 0.94 & $0.93,0.94$ & 35.57 & $0 \cdot 10$ \\
\hline High SDI & $75 \cdot 08$ & reference & & reference & & $36 \cdot 36$ & 0.11 \\
\hline \multicolumn{8}{|l|}{ Developmental grouping } \\
\hline EAG states & $53 \cdot 32$ & $-20 \cdot 71$ & $-20 \cdot 75,-20 \cdot 67$ & 0.72 & $0.71,0.72$ & $27 \cdot 23$ & 0.17 \\
\hline NE states & $63 \cdot 24$ & -10.79 & $-10 \cdot 90,10 \cdot 68$ & 0.85 & $0.85,0.86$ & $40 \cdot 65$ & $0 \cdot 10$ \\
\hline 'Other' states & $74 \cdot 03$ & reference & & reference & & $26 \cdot 89$ & $0 \cdot 10$ \\
\hline \multicolumn{8}{|l|}{ IBR-based grouping (tertiles) } \\
\hline Low: T1 (<93.8\%) & $44 \cdot 69$ & -34.43 & $-34.48,-34.39$ & 0.56 & $0.56,0.57$ & $40 \cdot 73$ & 0.12 \\
\hline Medium: T2 (93.8 to $97.8 \%)$ & $65 \cdot 75$ & -13.37 & $-13 \cdot 42,-13 \cdot 32$ & 0.83 & $0.83,0.83$ & $27 \cdot 23$ & 0.11 \\
\hline High: T3 ( $\geq 97.9 \%)$ & $79 \cdot 12$ & reference & & reference & & $13 \cdot 31$ & 0.06 \\
\hline
\end{tabular}

$\mathrm{CD}$, coverage difference; $\mathrm{Cl}$, confidence interval; $\mathrm{CR}$, coverage ratio; $\mathrm{CV}$, coefficient of variation; EAG, empowered action group; GC, Gini coefficient; IBR, institutional birth rate; NE states, northeast states; SDI, socio-demographic index.

While analysing coverage variations between subgroups (in a particular grouping), the subgroup with highest coverage (\%) was considered as reference.

is low ${ }^{(23,42)}$. Therefore, considering the same route and similar timing of administration, the poor coverage of vitamin $\mathrm{K}_{1}$ (despite the operational advantages) vis-à-vis HBV is especially noteworthy and the reasons thereof merit closer examination. In particular, some populous states with low socio-demographic indicators (e.g. Bihar and Uttar Pradesh) and some states in remote and frontier locations (e.g. Andaman \& Nicobar Islands, Arunachal Pradesh, Nagaland, Sikkim and Tripura) displayed stark differences in the coverage of vitamin $\mathrm{K}_{1}$ and $\mathrm{HBV}$ birth doses. In light of the above, the barriers are possibly specific to vitamin $\mathrm{K}_{1}$ prophylaxis and perhaps situated more proximally in the causal pathway. In the past, quality improvement interventions had led to improved neonatal health services (including vitamin $\mathrm{K}_{1}$ injection) in selected health institutions from India ${ }^{(43)}$. Nonetheless, from the implementation point of view, systematic steps are essential to identify and overcome the critical barriers that had affected the newborn vitamin $\mathrm{K}_{1}$ prophylaxis programme.

Interestingly, certain states (viz., Assam, Chandigarh, Goa, Gujarat, Himachal Pradesh, Jharkhand, Maharashtra, Meghalaya, Mizoram, Odisha) exhibited patterns that stood out as exceptions to the national trends. The coverage of vitamin $\mathrm{K}_{1}$ prophylaxis among newborns in these states was more than that of OPV and/or HBV. From the estimates in the individual states/UT and the various subgroups, it appears that a combination of factors (rather than a single factor) were responsible for the coverage disparities.
Anecdotal experiences indicate that factors such as adequate and timely supplies, stockouts, availability of supporting infrastructure (e.g. when there is a need for cold-chain maintenance), knowledge and awareness, accountability, attitude and motivation and the perceived priorities of the health workers can play a critical role at the ground level in influencing newborn services ${ }^{(16,40)}$. Besides, the first postnatal check is a good opportunity for contact with the newborn-mother pair during which health workers may offer services missed at the time of birth (if still within the recommended timeframe). Findings from the National Family Health Survey-4 report unveiled that the timing of the first postnatal check after birth (whether less than $4 \mathrm{~h}, 4-23 \mathrm{~h}, 1-2 \mathrm{~d}$ or 3-41 d) as well as the type of health provider providing that check (viz., doctor, nurse, midwife, lady health visitor, trained birth attendant, accredited social health activist, etc.) varies considerably across the different states/UT of India ${ }^{(44)}$. It is plausible that the heterogeneity in the coverage of vitamin $\mathrm{K}_{1}, \mathrm{HBV}$ and OPV at birth were related to these factors, too. Health systems/ service delivery in different states and UT of India have discernible differences with respect to key inputs and processes such as human resources, infrastructural facilities, quality accreditation, reporting mechanisms and utilisation of funds by the implementation agencies ${ }^{(45)}$. Thus, such counter-intuitive patterns in a country like India (which has enormous variations and diversity in health and healthcare; often called 'nations within a nation' ${ }^{,(24,25)}$ ) may be an 
outcome of the specific on-site scenarios in the concerned states/UT. It is also a reflection of the reality that a nationwide generalised 'one-size fits all' solution may not be applicable. For effective implementation of vitamin $\mathrm{K}_{1}$ prophylaxis throughout the country, customised interventions that take into account the challenges and context of the individual states/UT would be necessary.

\section{Limitations}

The HMIS is a major source of India's health-related information that has expanded, evolved, improved and strengthened over the years. To the best of knowledge, HMIS is the only source of routinely collected and publicly accessible nationwide vitamin $\mathrm{K}_{1}$ prophylaxis data in India. However, there were certain limitations in the study. Although the HMIS currently collates data from nearly 200000 health facilities all over the country, it still does not cover all health facilities (e.g. data from private health facilities is rather limited). That may have introduced some bias in the estimates. But that bias was potentially minimised by the extensive reach of the HMIS network (e.g. more than $20 \cdot 2$ million or nearly $80 \%$ babies born in the country ${ }^{(12)}$ were encompassed in this study). Besides, data quality for selected health indicators showed deviations between HMIS-reported data and data reported from surveys (e.g. National Family Health Survey-4) during a NITI Aayog evaluation ${ }^{(45)}$. These deviations varied according to the evaluated indicators and also across the individual states and UT. Since the reporting of vitamin $\mathrm{K}_{1}$ prophylaxis was not evaluated in that exercise, its data quality is unknown and therefore may be interpreted with caution. The study had other limitations as well. It could not capture the 'immediate reasons' (viz., insufficient supply, poor awareness of health workers, parental refusal, etc.) responsible for the gaps in vitamin $\mathrm{K}_{1}$ coverage. It also could not ascertain the health outcomes in babies who received vitamin $\mathrm{K}_{1}$ prophylaxis $v$. babies who did not. These aspects were beyond the scope of this report, and require exploration through future studies.

\section{Conclusion}

In conclusion, this report describes the coverage of vitamin $\mathrm{K}_{1}$ prophylaxis among newborns in India. In spite of operational guidelines for universal prophylaxis, extensive gaps and inequalities in coverage were evident. Overall, more than one-third newborn children were not supplemented with prophylactic vitamin $K_{1}$ during the 2019-2020 period. The situation was not uniform across the country, and varied according to geographical location, sociodemographic variables, developmental factors and rate of institutional deliveries. There were wide disparities in coverage amongst the different states and UT. Further sociobehavioural and health systems research are warranted to uncover the root causes and 'immediate reasons' that had hindered the practice of vitamin $\mathrm{K}_{1}$ supplementation in India. In addition, the health burden attributable to the gaps in coverage should also be investigated. Continuous vigilance, regular monitoring and multisectoral coordination will be crucial for a successful newborn vitamin $\mathrm{K}_{1}$ prophylaxis programme in the country.

\section{Acknowledgements}

Acknowledgements: I am grateful to the ICMR-Advanced Centre for Evidence Based Child Health (ACEBCH) at the Department of Pediatrics, PGIMER Chandigarh (India) for the wonderful capacity building activities and constant motivation. I also reminisce and thank Dr. Pallabi Konwar (Surveillance Medical Officer, NPHSP, WHO India) for the interesting discussions we had about the challenges that affect maternal and child health services in India. Further, I acknowledge the administrative support from Dr. K. Narain and Dr. S.K. Sharma. Financial support: No financial support was received for this work. Conflict of interest: There are no conflicts of interest. Authorship: K.B. conceived the study, analysed the data, interpreted the findings, drafted the manuscript and finalised it. Etbics of buman subject participation: Not applicable

\section{Supplementary material}

For supplementary material accompanying this paper visit https://doi.org/10.1017/S1368980021003670

\section{References}

1. Tie J-K \& Stafford DW (2016) Structural and functional insights into enzymes of the vitamin $\mathrm{K}$ cycle. $J$ Thromb Haemost 14, 236-247.

2. Shearer MJ, Fu X \& Booth SL (2012) Vitamin K nutrition, metabolism, and requirements: current concepts and future research. Adv Nutr 3, 182-195.

3. Araki S \& Shirahata A (2020) Vitamin K deficiency bleeding in infancy. Nutrients 12, 780.

4. Shearer MJ (2009) Vitamin K deficiency bleeding (VKDB) in early infancy. Blood Rev 23, 49-59.

5. Hasbaoui BE, Karboubi L \& Benjelloun BS (2017) Newborn haemorrhagic disorders: about 30 cases. Pan Afr Med J 28, 150 .

6. Elalfy MS, Elagouza IA, Ibrahim FA et al. (2014) Intracranial haemorrhage is linked to late onset vitamin K deficiency in infants aged 2-24 weeks. Acta Paediatr 103, e273-e276.

7. Schulte R, Jordan LC, Morad A et al. (2014) Rise in late onset vitamin $\mathrm{K}$ deficiency bleeding in young infants because of omission or refusal of prophylaxis at birth. Pediatr Neurol 50, 564-568.

8. Williams V, Jayashree M, Bansal A et al. (2019) Spontaneous intracranial haemorrhage in children-intensive care needs and predictors of in-hospital mortality: a 10-year singlecentre experience. Childs Nerv Syst 35, 1371-1379.

9. Zurynski Y, Grover CJ, Jalaludin B et al. (2020) Vitamin K deficiency bleeding in Australian infants 1993-2017: an 
Australian paediatric surveillance unit study. Arch Dis Child 105, 433-438.

10. Sankar MJ, Chandrasekaran A, Kumar P et al. (2016) Vitamin $\mathrm{K}$ prophylaxis for prevention of vitamin $\mathrm{K}$ deficiency bleeding: a systematic review. J Perinatol 36, S29-S35.

11. World Health Organization (2018) WHO Recommendations: Intrapartum Care for a Positive Childbirth Experience. Geneva: WHO. http://www.who.int/reproductivehealth/ publications/intrapartum-care-guidelines/en/ (accessed December 2020).

12. United Nations (2019) World Population Prospects 2019. Volume II: Demographic Profiles. New York: Department of Economic and Social Affairs, Population Division, UN. https://population.un.org/wpp/Publications/Files/WPP2019_ Volume-II-Demographic-Profiles.pdf (accessed December 2020).

13. Mathur MR \& Reddy KS (2019) Child health policies in India: moving from a discernible past to a promising future. Indian J Pediatr 86, 520-522.

14. Million Death Study Collaborators (2017) Changes in causespecific neonatal and 1-59 month child mortality in India from 2000 to 2015: a nationally representative survey. Lancet 390, 1972-1980.

15. Rai RK, Luo J \& Tulchinsky TH (2017) Vitamin K supplementation to prevent hemorrhagic morbidity and mortality of newborns in India and China. World J Pediatr 13, 15-19.

16. Kamate M \& Reddy NA (2019) Vitamin K prophylaxis: is there a need for policy change? Indian J Pediatr 86, 975-976.

17. Ministry of Health and Family Welfare (MoHFW) (2014) Operational Guidelines. Injection Vitamin K Prophylaxis at Birth (In Facilities). New Delhi, India: Child Health Division, MoHFW, Government of India. https://nhm.gov. in/images/pdf/programmes/child-health/guidelines/Vitamin K_Operational_Guidelines.pdf (accessed December 2020).

18. Ministry of Health and Family Welfare (MoHFW), WHO \& UNICEF (2009) Facility Based IMNCI (F-IMNCI) Participant's Manual. New Delhi, India: MoHFW, Government of India.

19. Ministry of Health and Family Welfare (MoHFW) (2014) INAP: India Newborn Action Plan. New Delhi, India: Child Health Division, MoHFW, Government of India. https:// nhm.gov.in/images/pdf/programmes/inap-final.pdf (accessed December 2020).

20. Ministry of Health and Family Welfare (MOHFW), HMIS Division \& National Health Systems Resource Centre (2011) Service Providers' Manual - Understanding Health Management Information Systems: Volume I. New Delhi, India: National Rural Health Mission, MoHFW; and HMIS Division, NHSRC, Govt. of India.

21. Ministry of Health and Family Welfare (MoHFW), HMIS Division \& National Health Systems Resource Centre (2011) Health Programme Managers' Manual Understanding Health Management Information Systems: Volume II. New Delhi, India: National Rural Health Mission, MoHFW; and HMIS Division, NHSRC, Govt. of India.

22. Vashishtha VM \& Kumar P (2013) 50 years of immunization in India: progress and future. Indian Pediatr 50, 111-118.

23. Ministry of Health and Family Welfare (MoHFW) (2017) Frequently Asked Questions on Immunization: For Health Workers and Other Front-Line Functionaries. New Delhi, India: MoHFW, Government of India.

24. Indian Council of Medical Research (ICMR), Public Health Foundation of India (PHFI) \& Institute for Health Metrics and Evaluation (IHME) (2017) India: Health of the Nation's States - The State-Level Disease Burden Initiative. New Delhi, India: ICMR, PHFI, and IHME. https://www. healthdata.org/sites/default/files/files/policy_report/2017/ India_Health_of_the_Nation\%27s_States_Report_2017.pdf (accessed December 2020).
25. India State-Level Disease Burden Initiative Collaborators (2017) Nations within a nation: variations in epidemiological transition across the states of India, 1990-2016 in the Global Burden of Disease Study. Lancet 390, 2437-2460.

26. Kumar V \& Singh P (2016) Access to healthcare among the Empowered Action Group (EAG) states of India: current status and impeding factors. Natl Med J India 29, 267-273.

27. Arora NK, Swaminathan S, Mohapatra A et al. (2017) Research priorities in maternal, newborn, \& child health \& nutrition for India: an Indian council of medical researchINCLEN initiative. Indian J Med Res 145, 611-622.

28. Castillo-Salgado C, Schneider C, Loyola E et al. (2001) Measuring health inequalities: Gini coefficient and concentration index. Epidemiol Bull 22, 3-4.

29. Brown MC (1994) Using gini-style indices to evaluate the spatial patterns of health practitioners: theoretical considerations and an application based on Alberta data. Soc Sci Med 38, 1243-1256.

30. Alonge O \& Peters DH (2015) Utility and limitations of measures of health inequities: a theoretical perspective. Glob Health Action 8, 27591.

31. Takahashi D, Shirahata A, Itoh S et al. (2011) Vitamin K prophylaxis and late vitamin $\mathrm{K}$ deficiency bleeding in infants: fifth nationwide survey in Japan. Pediatr Int 53, 897-901.

32. Busfield A, Samuel R, McNinch A et al. (2013) Vitamin K deficiency bleeding after NICE guidance and withdrawal of Konakion neonatal: British paediatric surveillance unit study, 2006-2008. Arch Dis Child 98, 41-47.

33. Shearer MJ (2020) Delivering neonatal vitamin K prophylaxis: the continuing need for surveillance and vigilance. Arch Dis Child 105, 417-418.

34. Ng E \& Loewy AD (2018) Position statement: guidelines for vitamin $\mathrm{K}$ prophylaxis in newborns: a joint statement of the Canadian paediatric society and the college of family physicians of Canada. Can Fam Physician 64, 736-739.

35. Mihatsch WA, Braegger C, Bronsky J et al. (2016) Prevention of vitamin $\mathrm{K}$ deficiency bleeding in newborn infants: a position paper by the ESPGHAN committee on nutrition.J Pediatr Gastroenterol Nutr 63, 123-129.

36. Majid A, Blackwell M, Broadbent RS et al. (2019) Newborn vitamin K prophylaxis: a historical perspective to understand modern barriers to uptake. Hosp Pediatr 9, 55-60.

37. Marcewicz LH, Clayton J, Maenner M et al. (2017) Parental refusal of vitamin $\mathrm{K}$ and neonatal preventive services: a need for surveillance. Matern Child Health J 21, 1079-1084.

38. Phillippi JC, Holley SL, Morad A et al. (2016) Prevention of vitamin K deficiency bleeding. J Midwifery Womens Health 61, 632-636.

39. Loyal J \& Shapiro ED (2020) Refusal of intramuscular vitamin K by parents of newborns: a review. Hosp Pediatr 10, 286-294.

40. Coffey PS \& Gerth-Guyette E (2018) Current perspectives and practices of newborn vitamin $\mathrm{K}$ administration in low- and middle-income countries. Res Rep Neonatol 8, 45-51.

41. Bang AT, Bang RA, Baitule SB et al. (1999) Effect of homebased neonatal care and management of sepsis on neonatal mortality: field trial in rural India. Lancet 354, 1955-1961.

42. Khan J, Shil A \& Mohanty SK (2019) Hepatitis B vaccination coverage across India: exploring the spatial heterogeneity and contextual determinants. BMC Public Health 19, 1263.

43. Sarin E, Kole SK, Patel R et al. (2017) Evaluation of a quality improvement intervention for obstetric and neonatal care in selected public health facilities across six states of India. $B M C$ Pregnancy Childbirth 17, 134.

44. International Institute for Population Sciences (IIPS) \& ICF (2017) National Family Health Survey (NFHS-4), 2015-16: India. Mumbai, India: IIPS.

45. NITI Aayog, World Bank \& Ministry of Health and Family Welfare (2019) Healthy States Progressive India: Reports on the Ranks of States and Union Territories. New Delhi, India: NITI Aayog, Government of India. 